\title{
O MUNDO COMO ESPAÇO: MAPAS COMO REPRESENTACÕES QUE CONSTROEM E TRANSFORMAM O ENTORNO QUE PERCEBEMOS E OCUPAMOS
}

\author{
Yago Quiñones Triana \\ Universidade de Brasília (UnB), DF, Brasil \\ yagoat@gmail.com
}

\begin{abstract}
RESUMO
O artigo trata sobre o surgimento da ideia de mundo como espaço e a função dos mapas neste processo. O intento é compreender o entorno físico que ocupamos a partir do conceito de espaço (mesmo o desabitado, vazio), e não por uma ocupação humana concreta do território. $O$ trabalho foca no projeto histórico de racionalizar e regularizar cientificamente o mundo que experimentamos. Neste contexto, o mapa apresenta um papel essencial, ao ser a representação gráfica que ratifica essa visão de mundo, ao mesmo tempo em que influencia a nossa própria compreensão dele. Deste modo, o texto propõe uma breve abordagem histórica sobre a consolidação do conceito de mundo como espaço a partir do processo de desenvolvimento dos produtos cartográficos.
\end{abstract}

Palavras-chave: Espaço. Mapas. Modernidade. Meshwork.

\section{THE WORLD OF SPACE: MAPS AS REPRESENTATIONS THAT CONSTROY AND TRANSFORM THE ENVIRONMENT THAT WE PERCEIVE AND OCCUPY}

\begin{abstract}
The article deals with the emergence of the idea of world as space and the function of maps in this process. The aim is to understand the physical environment we occupy from the concept of space (even the uninhabited, empty), and not by a concrete human occupation of the territory. Then it focuses on the historical project of rationalizing and scientifically regularizing the world we experience. In this context, the map plays an essential role, being the graphic representation that ratifies this worldview, while influences our interpretation of it. Thus, the paper proposes a brief historical approach on the consolidation of the concept of world as a space from the process of development of cartographic products.
\end{abstract}

Keywords: Space. Maps. Modernity. Meshwork.

\section{INTRODUÇÃO}

Entre as noções que utilizamos para descrever o mundo em que habitamos, a de "espaço" parece ser a mais abstrata e distante da realidade cotidiana, a mais vazia (INGOLD, 2011). A intuição, o sentido comum, nos diz que o espaço é uma dimensão externa e preexistente à nossa experiência. Uma dimensão que exploramos durante a vida, já que aparentemente o espaço se faz presente antes da nossa ação começar, e serve de cenário para o nosso percurso, permanecendo após a nossa saída desse mundo (INGOLD, 2011). Portanto, o que há no espaço no qual ocorre a existência humana? Sabemos que em dito espaço somos capazes de identificar uma série de "pontos", embora que não necessariamente fixos, espécies de balizas ou referências significativas nas quais podemos reconhecer nossa estada pelo mundo. São lugares familiares que quebram o que de outro modo seria a plana monotonia do espaço. Esses lugares, que podemos reconhecer e que neles nos reconhecemos por fazer parte da sua construção, encontram-se disseminados no espaço (INGOLD, 2011). Estes lugares nos trazem uma experiência concreta e perceptível, enquanto que do espaço entre eles não podemos dizer a mesma coisa. Aliás, o conceito de espaço começa a surgir na nossa mente por constatação negativa: por aquilo que não é lugar. Surge como vazio em contraponto ao lugar, onde possuímos referencias claras (INGOLD, 2011). Além disso, o espaço não faz parte da dimensão concreta da nossa existência, como o conceito de natureza, por exemplo, o qual forma uma parte do "mundo afora" que habitamos. Portanto, sendo o vespaço um vazio como faz parte da dimensão concreta da existência?

Mais do que o resultado de uma constatação, o conceito de espaço responde a uma visão específica do entorno ocupado pelo ser humano. A visão é complexa, sendo reconhecida em vários campos das práticas sociais e, sem dúvida, atualmente se estabelece como o enfoque predominante, pois responde e é parte importante dum projeto racionalizado de interpretação do mundo físico, que corre de forma paralela com a consolidação da sociedade ocidental. Trata-se do projeto explícito de domesticar a realidade externa 
adaptando-a à parâmetros objetivos e mensuráveis, para assim estandardizar a experiência individual do entorno e reduzi-la a marcos científicos, o que possibilita, dentre outros processos, desenvolver representações pretendidamente fiéis de tal realidade (MATTELART, 2002). Assim, é claro que a forma como se interpreta o entorno decorre de vários fatores de ordem social, histórica, cultural e cientifica e daí surgem várias ferramentas gráficas, como a perspectiva lineal na pintura do renascimento e o plano cartesiano, que fixam tal interpretação. No entanto, estas ferramentas gráficas não são simples repositórios das nossas ideias sobre o mundo que ocupamos, mas também acabam influenciando estas mesmas ideias. No caso, o mapa se caracteriza como um instrumento complexo, simbólico, que sintetiza muito bem no seu desenvolvimento histórico as tentativas de racionalizar e controlar o território por meio de sua representação, o qual traz consequências evidentes nas formas como entendemos e nos relacionamos com a realidade física que ocupamos. A evolução do mapa pode ser vista como a tentativa de conceitualizar graficamente a ideia de que o nosso entorno físico estaria constituído mais pelo espaço (vazio) que pela vivência humana, isto é, pelos percursos que unem os pontos fixos do mapa. A seguir se verá, a partir do desenvolvimento do mapa, como esta ferramenta tem participado na construção da ideia do mundo como espaço, e de que forma, sendo uma representação do mesmo, tem influenciado na transformação das formas em que o pensamos.

\section{A CRIAÇÃO ESTATÍSTICA DO ESPAÇO ENQUANTO TERRITÓRIO}

No século XVII, surge na Europa ocidental a ideia de "território" baseada na ciência estatística - a ciência do Estado - que começava a nascer. Em outras palavras, a estatística faz uso de dados numéricos para compreender os fenômenos sociais, constituindo-se como uma ferramenta para gerenciar unidades políticas. Sébastien Le Prestre de Vauban, engenheiro militar na França de Luis XIV, é quem vai dar um impulso sem precedentes ao projeto de quadricular o corpo da terra (MATTELART, 2002). O engenheiro teve a firme e explícita intenção de, na sua visão, sair do caos e da confusão por meio de uma conduta regulada pelo cálculo, padronizando a superfície do reino francês ao desenvolver uma série de instrumentos de coleta e, sobretudo, geração de informações. Neste momento, a extensão territorial da nação passa a ser vista não mais como uma entidade autônoma, e sim como um objeto passível de registro e organização, ao qual era possível aplicar certas ferramentas científicas para gerar uma forma de um novo conhecimento, que privilegiava o cálculo na experiência sobre o território.

Vauban concebe um "sistema de fortificações", não mais separadas, mas ligadas formando uma corrente interconectada que identificasse os limites do país (Figura 1) - fase embrionária da ideia de rede - começa a se consolidar um projeto de representação da superfície da nação, ou seja, criação do território e construção do espaço, o qual atingira sua expressão mais explícita na elaboração do plano gráfico ou planorelevo para cada praça. Esses planos constituíam uma importante síntese de informações e serviam como modelo e retrato para os administradores do Estado (MATTELART, 2002).

Figura 1 - Linhas defensivas e fortificações francesas na fronteira com os Países Baixos ${ }^{1}$.

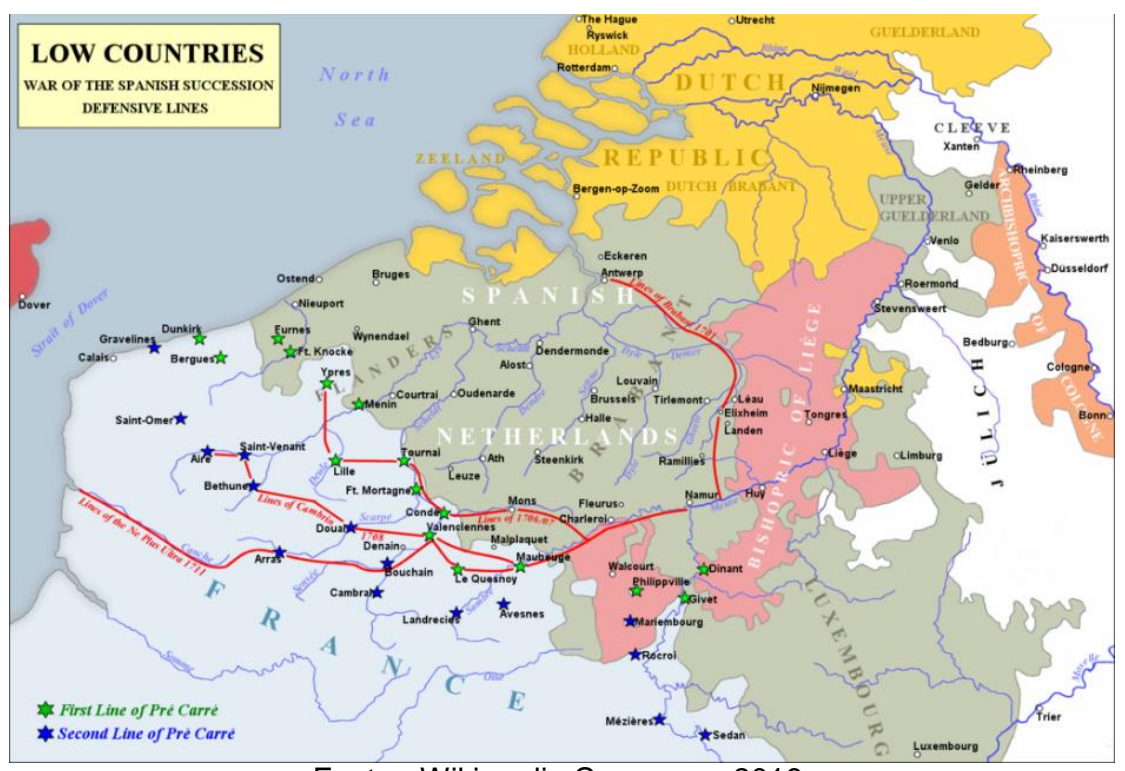

Fonte - Wikimedia Commons, 2019

\footnotetext{
${ }^{1}$ Nesta imagem vemos as fortificações de Vauban na fronteira da França organizadas segundo um sistema que as ligava e criava um circuito que dava forma concreta e física ao território definido politicamente.
} 
Tratava-se de representações da realidade geográfica subordinadas a uma lógica que privilegiava uma "perspectiva reticular", capaz de produzir uma grelha ${ }^{2}$ de análise alheia aos pormenores acidentais do terreno ou da cultura. A "utopia geometral", isto é, o projeto utópico de reduzir todo o território a parâmetros objetivos e mensuráveis, levara, anos depois, a divisão do território seguindo critérios normativos que acabariam por esquecer o mundo, alimentando os comentários irônicos dos vizinhos ingleses como Edmund Burke que, em 1790, sentencia lucidamente: "Nunca se ha sabido de hombres ligados por el orgullo, una inclinación o un sentimiento profundo, a un rectángulo o a un cuadrado." (MATTELART, 2002, p. 30).

Todas essas tentativas de organização racional do entorno físico e, consequentemente social, fazem parte dum projeto muito mais amplo que vivia a sociedade ocidental em face à Modernidade. Contudo, o resultado que mais chama a atenção é a gradual consolidação de mecanismos que participam no processo de representação do mundo físico e, portanto, de construção do espaço como noção moderna. Isto possibilita uma forma de representação específica que traz e sustenta a ideia do espaço como um conceito abrangente e anterior ao âmbito concreto da experiência humana. Do ponto de vista da engenharia militar, o objetivo era identificar e localizar num modelo racional os pontos relevantes da realidade para a estratégia belicista. Criava-se então, uma representação do terreno objetiva e asséptica, onde a prioridade estava na precisão, na localização dos lugares relevantes e, muito importante, na distância entre elos pontos/áreas. Não é uma casualidade que nos tempos de Vauban a arte da guerra deva incluir a balística entre suas especialidades, com o cálculo de trajetórias baseados em noções físicas fundamentais, que padronizam precisamente a relação simbiótica entre as dimensões de tempo e espaço (MATTELART, 2002). Não era mais necessário ir até o lugar real para corroborar a situação de contexto, já que a sua representação fiel, baseada num padrão objetivo, permitia conhecer as posições, as distâncias e todas as informações relevantes como "estando lá". Inclusive as estratégias militares de ação, reais, podiam ser estabelecidas sobre o papel, que era uma representação confiável e instrumental da realidade.

A aplicação do espaço como noção que se expressava graficamente na forma de uma grelha que se sobrepõe à realidade, para dar uma localização precisa para cada objeto, também padronizava o que há "entre" estes objetos, isto é, aquele espaço que vira uma distância, um dado quantificável ao qual se atribui um significado numérico ao que representa potencialmente um vazio: o espaço inabitado. Deste modo, gerase uma interpretação a partir de uma ferramenta abstrata que subordinava a importância da realidade a um critério de localização, esvaziando semanticamente toda interpretação do terreno proveniente da vivência de quem o ocupa, por ser incoerente com a visão dum espaço homogêneo e abstratamente objetivo. Por meio de uma abstração teórica de corte matemático e geométrico se procurava atingir um caráter objetivo na representação do mundo, conseguindo com isso somente objetivá-lo.

Dentro de todo este processo, o mais interessante é observar a relação entre a representação do mundo e o mundo físico-concreto, ou seja, a própria realidade representada, e de que forma a representação gráfica pode exercer influência no modelo a partir do qual ela, em teoria, surge. Mais ainda, a "raiva matemática" que nega a paisagem criada pela história (MATTELART, 2002), contribuiu numa representação do mundo que acaba por criar um outro: o mundo do espaço. Trata-se de um mundo caraterizado pelo fato de ser ocupado e não mais habitado (INGOLD, 2011). Sendo assim, temos um modelo representacional fortemente ancorado na ideia de espaço como conceito abstrato, que termina produzindo uma ideia de mundo com características próprias e definidas, ao ponto de poder falar até mesmo em um "mundo do espaço". É claro, não estamos dizendo que haja um mundo real e uma espécie de mundo ficcional construído a partir da prática representacional geométrica, mas que a forma como o representamos constrói a própria realidade perceptiva do mundo. Neste caso, a percepção do mundo tem como principal alicerce a noção de espaço que, como vimos, é fortemente construída a partir do ideário predominante a uma determinada época, e não nasce da experiência, mas de um projeto intelectual e cientifico. Talvez o exemplo mais concreto desta situação seja o desenvolvimento de uma ferramenta que, melhor que outras, pode sintetizar o projeto de fixação do mundo do espaço como visão da realidade: o mapa.

\section{O MAPA COMO REPRESENTAÇÃO DO ESPAÇO}

O mundo do espaço tem, precisamente, o espaço como conceito fundante, e o mapa como a sua forma básica de representação. A noção ocidental moderna e familiar de mapa apoia-se fortemente no conceito de espaço e na sua aplicação para a geração de uma imagem capaz de visibilizar o vazio que ele representa. Para chegar, porém, nesta fase, em que o mapa se consolida como uma forma privilegiada de representar o espaço, se deve voltar atrás na evolução desta ferramenta para entender como ajudou a conceber justamente a própria ideia de espaço. A partir do século XVI, os impérios marítimos ibéricos concorrentes entram numa nova disputa, a de traçar mapas confiáveis das costas dos seus territórios para servir como

\footnotetext{
${ }^{2}$ No sentido de uma quadrícula: rede de linhas horizontais e verticais que formam um conjunto de pequenos quadrados ordenados.

Caminhos de Geografia $\quad$ Uberlândia $\quad$ v. 21, n. $73 \quad$ Mar/2020 $\quad$ p. 199-208 Página 201
}


ferramentas supostamente objetivas para a exploração e a navegação, mesmo sendo ainda não cientificas, já que não contavam em sua elaboração com procedimentos estritos e padronizados (TURNBULL, 1996). O projeto explícito era manter sob controle político os novos domínios, potencialmente em contínua disputa, por meio do controle simbólico surgido da domesticação do território a partir das linhas rigorosas do mapa. A vontade de estandardizar os conhecimentos acumulados num suporte de caráter universal levou a Espanha e Portugal à tentativa de produzir o Padrão Geral: um mapa capaz de guiar todas as rotas marítimas no império (TURNBULL, 1996). A criação de um mapa síntese padronizava de forma geral todo o território, tratando-se assim, de um ato estatal para monopolizar o conhecimento empírico acumulado. De forma concomitante com outras funções da Casa de Contratación de Sevilla e da Casa da Índia, instituições encarregadas de realizar o Padrão Geral, a intenção clara era garantir o domínio da Coroa nas colônias, exercendo um controle absoluto aos olhos das outras potencias europeias. Neste caso, a realização de um mapa geral, com a pretensão de ser objetivo, encarregado a especialistas com a tarefa específica de sintetizar o saber vivencial e local dos navegantes, era um ato de poder imperial que devia ter um valor geral, universal. O ambicioso projeto não teve sucesso e o Padrão Geral foi abandonado na metade do século XVI (TURNBULL, 1996), porém, é um exemplo paradigmático de uma mentalidade nascente, limitada pelos recursos técnicos, mas que demonstra claramente o início da consolidação do mundo do espaço e Ocidente.

O Padrão Geral não vingou porque tecnicamente era uma "carta portulana" (Figura 2), ou seja, uma ferramenta cartográfica que não estava baseada no cálculo geométrico e sem uma base matemática. As cartas portulanas representaram uma importante tentativa de se afastar do modelo dos mapas medievais anteriores e seu conteúdo teológico intrínseco (CAMPBELL, 1987). Ainda sendo considerados como mapas medievais (GOMES e DE BIASI, 2015), tratava-se dos mapas mais exatos produzidos até o momento, se distinguindo da maior parte da cartografia medieval caracterizada pelo intento de fazer uma ilustração decorativa de textos religiosos (RAISZ, 1969). Pelo contrário, é possível que as cartas protulanas fossem ideadas por marinheiros na tentativa de produzir ferramentas que ajudassem a guiar as rotas marítimas. Se caracterizavam assim pela introdução de símbolos que pretendiam universalizar sua leitura, demonstrando o espírito prático que os inspirava, se esperava que pudessem orientar marinheiros que não conheciam as costas neles representadas (GOMES E DE BIAISI, 2015). Trata-se de documentos fundamentais na evolução da cartografia entre o final da idade média e o começo da era moderna europeia (CAMPBELL, 1987). Porém, embora apresentasse graficamente uma grelha, esta não respondia a um padrão numérico objetivo, não havia uma correspondência entre a quadricula desenhada e uma determinada forma de medir o espaço. Isto não permitia uma homogeneidade nas distâncias dos percursos, que, aliás, ainda eram influenciados pela força dos ventos (TURNBULL, 1996), não podendo assim registrar o espaço objetivo percorrido, mas o percurso subjetivo de cada navegante segundo a sua experiência. É então evidente que o projeto de unificar vários percursos locais num padrão geral ia trazer vários problemas de coerência, como efetivamente aconteceu, e os navegantes voltaram aos seus recursos anteriores que eram mais confiáveis embora que reduzidos geograficamente a determinadas rotas locais (TURNBULL, 1996). O espaço, abstrato, homogêneo, universal, existia como estrutura teórica e política, mas não era ainda aplicável na prática da cartografia.

Figura 2 - Carta portulana do mundo velho (1505).

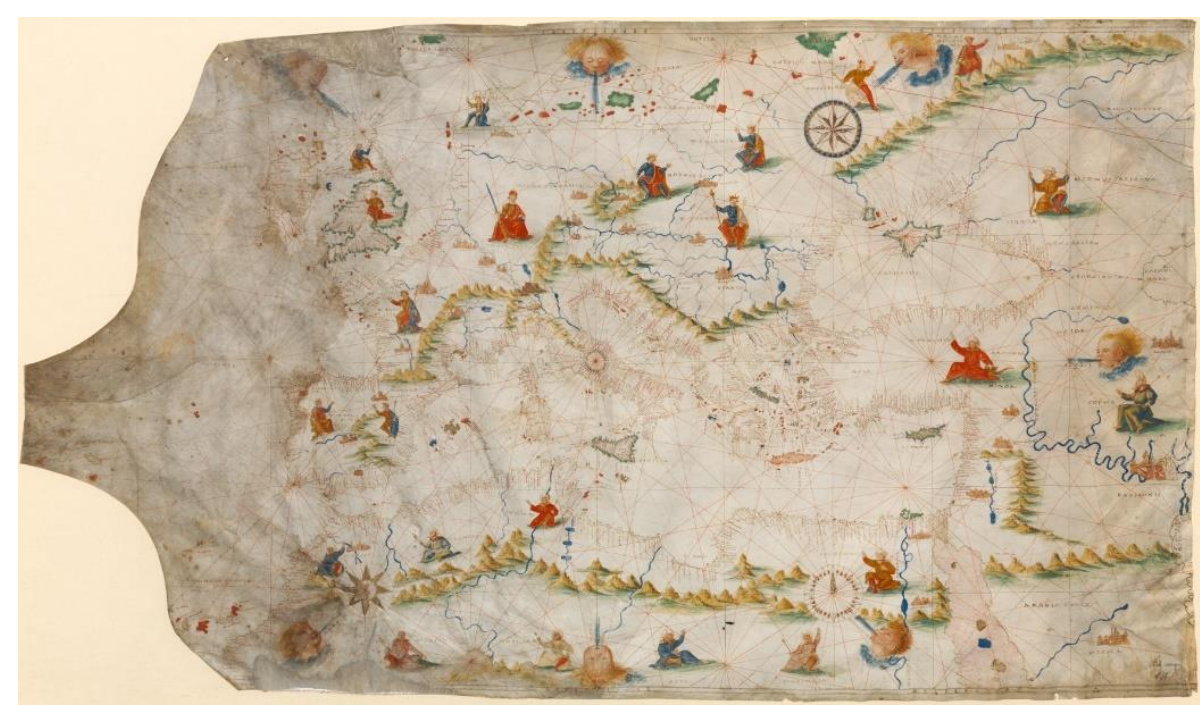

Fonte - Wikimedia Commons, 2019. 
Faz parte do mesmo processo a eliminação dos elementos icônicos, herança de tempos anteriores, onde os mapas indicavam sobre tudo um percurso, um traçado, no qual as distâncias podiam ser quantificadas em jornadas de caminho (DE CERTEAU, 2010). Nestes mapas não havia intenção alguma de trazer o mundo sobre o papel, na sua construção mediava uma representação do entorno altamente metafórica, tratando a figuração do mundo como um teatro, ao representar um microcosmos sintetizado esteticamente num suporte material. Tratava-se de uma referência literal, associada a arquitetura do teatro dramático que expressava uma espécie de obsessão no século XVI europeu pelas imagens e figuras sintéticas e esquemáticas do universo, espécies de palcos estetizantes onde se encenava o mundo (AKERMAN, 1995).

As formas de representação mudam no período de consolidação do Estado moderno e das grandes expedições europeias, ou seja, há uma importante mudança ao nível metafórico na produção dos mapas. A progressiva eliminação de elementos narrativos gráficos (navios, animais e diversas personagens) pode ser vista como uma crescente autonomia do mapa (DE CERTEAU, 2010), no qual as ilustrações ou comentários icônicos, que não são simples enfeites, mas registram um processo histórico na sua produção, são abandonados em detrimento da instauração da geometria como colonizadora dos espaços do mapa e que gera um novo contexto uniforme onde podem conviver justapostos os diversos elementos do território e os diversos conhecimentos acerca dele. Assim, se as cartas portulanas não puderam ser integradas num conjunto maior, num padrão, era porque elas surgiam da vivencia subjetiva e singular dos navegantes nas costas que thes eram familiares, nos seus percursos.

Estes mapas pré-modernos condensavam conhecimentos locais, integravam de forma literal alguns detalhes a partir de um enfoque descritivo (TURNBULL, 1996). Eram, em certo sentido, a representação gráfica do meshwork, conceito que substitui à ideia de network e traz a proposta de uma série de pontos unidos por linhas, com o princípio da rede da vida com as linhas entrelaçadas em nós que marcam o traçado da vivência onde (INGOLD, 2011). No network temos pontos e linhas como formas gráficas capazes de figurar o nosso ser no espaço, onde os pontos, os lugares, oferecem as coordenadas para o traçado (DE CERTEAU, 2010); o apoio objetivo para a definição dos percursos que, vistos como linhas, poderão unir os pontos e obter a clássica imagem da rede (network). Todavia, esta não é a única opção: e se ao invés das linhas unirem pontos predefinidos fosse o mesmo percurso subjetivo a definir os pontos externos do espaço? E se o importante não estivesse na união dos pontos, mas nas linhas que criam os nós? Aliás, é pertinente se perguntar qual a diferencia entre a figura a partir de dois pontos $A$ e $B$ que se relacionam a partir de linha $P$ e de duas linhas $A$ e $B$ que criam um ponto $P$ ao se cruzarem. Do ponto de vista estritamente geométrico não há nenhuma diferença essencial, mas se consideramos a figura geométrica da linha como sendo os percursos da nossa experiência, os nós ou interseções representariam interações entre sujeitos (INGOLD, 2011).

Em outras palavras, os lugares onde é possível identificar uma ação significante ao oferecer sentido à peregrinação do andarilho, não têm como objetivo chegar num local previamente localizado em uma abstração vazia do espaço, mas privilegia as redes que pode traçar neste percurso. "O que é comumente conhecido como a 'rede da vida' é precisamente isso mesmo: não um network de pontos conectados, mas um meshwork de linhas entretecidas" (INGOLD, 2011, p. 63). Isto porque, não deve haver somente práticas "espacializantes", mas "lugarizantes", que criam os percursos e também o substrato aparentemente objetivo no qual os sujeitos se desenvolvem e circulam. Portanto, é o fazer que dá vida ao espaço, logo, trata-se de uma prática geradora de espaço (DE CERTEAU, 2010), a qual se apoia especialmente no movimento, nos percursos que criam as narrações de cada sujeito no seu próprio espaço; "quem viaja tem muito que contar, diz o povo" (BENJAMIN, 1987, p. 198), já que "todo relato é um relato de viajem, uma prática do espaço" (DE CERTEAU, 2010, p. 128).Não mais um network, onde primam os pontos, mas um meshwork (INGOLD, 2011), com capacidade de organizar o rumo, seu traçado, mas também de gerar o lugar que se percorre no espaço.

Nos mapas pré-modernos, percebe-se uma vontade nascente de racionalização e padronização, ressaltando-se uma dada realidade que propõem as linhas e seu entrecruzamento, isto é, os percursos, neste caso as rotas dos viajantes que permitiam traçar um perfil do mundo, da terra. Contudo, a posterior evolução (moderna) dos mapas não demonstraria que a consolidação do espaço como categoria de compreensão do mundo traz o aparente esquecimento dos percursos dos sujeitos? Trata-se assim, da concretização do mundo do espaço: não mais habitado por agentes que registram seus percursos, mas 
padronizado por uma quadrícula que é totalmente invisível fora dos mapas. Ninguém jamais viu um meridiano, ninguém o experimentou, nem o registrou como um sinal no seu percurso, mas é evidente que a sua existência é comprovada a partir das consequências que traz para nossa cotidianidade.

\section{O MAPA: A REALIDADE EM DUAS DIMENSÕES}

Como o engenheiro militar Sébastien Le Prestre de Vauban, os gênios da cartografia moderna também desempenharam a difícil tarefa de fazer perceptível uma noção abstrata, a grelha geométrica homogênea e objetiva, e o fizeram por meio de uma outra abstração: a representação racional plana, em duas dimensões. Deste modo, o espaço é representado como plano e homogêneo, isto é, pode ser representado a partir de uma matriz uniforme e matemática, aplicada à realidade permitindo localizar objetos ou lugares, além de se poder calcular de forma objetiva, desconsiderando os individuais, as distâncias. Esta operação é possível desde o início da era moderna, já que havia a consciência de que a realidade representada não era plana. $E$ isto não tem a ver com os acidentes geológicos, mas com o caráter esférico da superfície representada. Da mesma forma que no caso da perspectiva renascentista, a qual lutava contra a evidencia de as imagens visuais do mundo não serem planas por causa da curvatura do globo ocular onde elas nascem (PANOFSKY, 2003), a cartografia também se enfrenta à evidencia física e adapta a realidade a um conceito teórico, à suposta superioridade prática da representação em duas dimensões da superfície terrestre redonda.

A partir do trabalho de Mercator, o traçado das rotas marítimas como linhas retas no mapa dava certeza aos navegantes, mas não se representava a menor distância entre dois pontos do globo, pois desconsiderava a curvatura da Terra ou, pelo menos, não deixava clara qual a relação entre as linhas retas e a esfericidade da superfície representada (CAMPBELL, 1987).Já que apresentava as linhas correspondentes aos rumos magnêticos como retas (RAISZ, 1969), entrando assim em conflito com o fato dos percursos marítimos ser sempre curvos, como tinha demonstrado já Pedro Nunes (TURNBULL, 1996). Inclusive a forma de atravessar o espaço subordinava o percurso à forma de representar o entorno, contornando a realidade empírica quase como um problema ou uma imperfeição aleatória. $O$ trabalho de Mercator representa o valor mais alto da idade de ouro da cartografia holandesa, que vá desde meados do século XVI até metade de 1700, e se caracteriza pela redescoberta de Ptolomeu, a influência da imprensa na reprodução e difusão dos mapas e a relevância geográfica das expedições europeias ao redor do mundo (RAISZ, 1969). Mercator é reconhecido especialmente pelo sistema de projeção de paralelos e meridianos como retas, o que fazia que a relação entre os dois tipos de linhas fosse certa somente em algumas áreas do mapa (RAISZ, 1969).

Com a consolidação do lluminismo ocorre uma ulterior mudança, especialmente na França, o Estado estava interessado em financiar homens de ciência para aprimorar a precisão cientifica dos mapas (RAISZ, 1969). Se na escola holandesa se dava prioridade à beleza dos mapas e à possibilidade de produzir um número importante de copias a serem vendidas, a academia francesa patrocinada pelo Rei perfeiçoa o sistema de triangulação, conseguindo uma determinação muito precisa das longitudes já no final do século XVII (RAISZ, 1969). O que levou ao primer levantamento cartográfico nacional com Luis XV e que seria imitado a seguir por vários outros estados. Tratava-se do espirito matemático racional visto acima com Vauban no âmbito militar, mas na área específica da cartografia.

Desta forma, historicamente a definição mais comum de mapa em Ocidente está relacionada a uma representação fiel do terreno, um certo espelho da realidade, o que acaba por naturalizá-lo como um objeto de conhecimento autónomo e eficaz. Tal naturalização possibilitou associar os mapas a capacidades cognitivas relacionadas a orientação espacial; mas de fato, essa capacidade humana não está diretamente associada ao uso de mapas, isto porque essas habilidades eram utilizadas antes do uso desses artifícios gráficos, os quais se fazem necessários em determinados contextos sociais (WOOD, 2010). Isso nos leva a considerar que as relações sociais podem se identificar com o triunfo do espaço como categoria abstrata de compreensão do entorno social e físico.

Ao se consolidar do espaço como forma de pensar o mundo, ou seja, com a implementação do mundo do espaço, o mapa cumpre a função básica de dar forma e concretude a essa realidade abstrata. O mapa medieval, com seus códigos altamente metafóricos vai cedendo lugar às versões cientificas que perdem seu poder estético em favor de uma importante função "proposicional". O mapa não quer ser mais uma representação do mundo, não quer mais contar o mundo sobre um papel, perde seu caráter narrativo 
associado à temporalidade do percurso do viajante. O mapa moderno quer fazer o mundo, ao produzir uma serie de proposições que organizam o espaço geográfico "como ele é" aos olhos do observador. A força do mapa moderno está em colocar num plano dois ou mais pontos que empiricamente uma pessoa não poderia relacionar. Perde-se totalmente a temporalidade narrativa que acentua o movimento de um lugar para outro, passando a privilegiar uma imagem sem relação com as contingências temporais dos percursos.

Perder-se-ia em parte a sua condição textual da representação, ao perder um tecido de narrações numa determinada temporalidade, mas por outro lado, privilegia a ideia de o mapa ser uma imagem que não exija uma leitura relacionada com uma duração, um tempo, devido a um tratamento visual e global que leva a construir uma nova realidade. Assim, o mapa se constitui como um objeto espacial, por assumir as suas características diferenciais enquanto permite uma leitura efetivamente espacial, isto é, quando propõe uma analogia que realmente funciona, na qual a mensagem leva a configuração espacial, a um conjunto sincrônico de relações entre fenômenos localizados (LÉVY, 1996). A sua ação é proposicional, ao afirmar que uma coisa ou lugar está ali, onde o mapa indica, com relação a outra num mesmo plano homogêneo e com as distâncias claramente acertadas na base de uma regra gráfica universal. Desta forma, o sujeito compreende como é o mundo lá fora, é capaz de adquirir uma realidade que excede seu alcance, sua visão, uma realidade a que não poderíamos chegar de outra forma (WOOD, 2010). O mapa não é mais uma metáfora do mundo, mas uma representação do mundo como ele é. É uma forma do mundo se expressar de maneira perceptível, é um método para ver o mundo. Como? Por meio de uma representação totalmente confiável, analógica.

\section{A FIDELIDADE POR MEIO DE TECNOLOGÍAS VISUAIS E "OBJETIVAS"}

Após a consolidação do mapa moderno, uma transformação técnica trouxe uma ulterior evolução desta ferramenta de comunicação. Assim como o surgimento da fotografia acabou em uma reconfiguração das formas visuais de representar o mundo, da mesma forma, a cartografia teve com a fotografia área (RAISZ, 1969) e as imagens de satélite a possibilidade de reforçar o seu poder de enunciação (COSGROVE, 2005). No mundo moderno, os mapas são auto-evidentes, pois mostram e demonstram a sua pertinência ao se estabelecerem como-objetos naturais ao replicarem digitalmente a estrutura física do mundo, expressando um fato geográfico (EDNEY, 1996). Afirma-se assim, que todo mapa moderno está baseado na ideia de espaço, sendo estruturado a partir dum suporte bidimensional que domina a nossa forma de produção de imagens. No entanto, a imagem visual - a que vemos, não a que produzimos - assim como a superfície terrestre, não é bidimensional, e sua representação num plano vai ser sempre uma redução. Uma tradução gráfica de uma realidade complexa. Já no século XVIII o matemático Leonhard Euler tinha demonstrado cientificamente, isto é, apoiando-se nas ferramentas e conceitos da ciência matemática, a impossibilidade de transportar para um plano uma superfície esférica de maneira confiável, sem deformações. Hoje é claro que a superfície terrestre, pela sua própria natureza imperfeita e não homogênea, não é apropriada para lidar com processamentos sistemáticos (ALVARENGA, 2002). Esta barreira "dimensional" aparentemente insuperável pareceria ser colocada em discussão a partir das potencialidades que traz o digital, e especificamente os mapas acessíveis através da Internet.

Hoje, várias ferramentas do mundo digital nos permitem ter acesso a interfaces, isto é, conexões funcionais entre dois sistemas, neste caso o usuário e um dispositivo, que a partir de um mapa aparentemente convencional, são capazes de oferecer diferentes informações pertinentes sobre o território representado. Gera-se assim, um recurso em teoria muito mais fiel à realidade representada, mais completo, mais apto para cumprir a tarefa de ser um apoio para entender e conhecer o entorno. A partir de imagens de satélite e utilizando uma rica base de dados, estes recursos permitem produzir mapas bastante sofisticados e, ao mesmo tempo fáceis de ler e utilizar, é praticamente como ter a disposição uma serie de satélites e as informações visuais que eles coletam da terra. Aparentemente é o fim definitivo do caráter metafórico dos mapas e, paralelamente, a consolidação total de sua virtude proposicional. Estes recursos, que cada vez possuem mais ferramentas para aprimorar a experiência do usuário, têm inovado na sua vocação de fidelidade à realidade chegando a um ponto extremo: fornecer uma superfície de representação que se apoia na ideia da terceira dimensão, no 3D (ver Figura 3). Como em outras áreas do paradigma visual contemporâneo, especialmente no cinema e nas artes, a tecnologia em 3D obriga a questionar a superfície 
de representação (QUIÑONES TRIANA, 2013), e na cartografia não é diferente. Intuitivamente, pode-se pensar que as formas de registro em terceira dimensão chegariam para completar o projeto de representação do mundo geográfico, superando inclusive o paradoxo de ter uma realidade que se adapta a uma representação plana e ordenada, subordinando-se a um regime visual reduzido a duas dimensões. Se, com o 3D os mapas deixam de ser (supostamente) planos, eles poderiam potencialmente aperfeiçoar sua vocação de propositores de uma determinada realidade geográfica. Todavia, esta potencialidade não é totalmente desenvolvida pois ainda mantemos um paradigma de representação que privilegia às duas dimensões e o plano como matriz para geração das imagens.

Figura 3 - Interface do programa Google Earth.

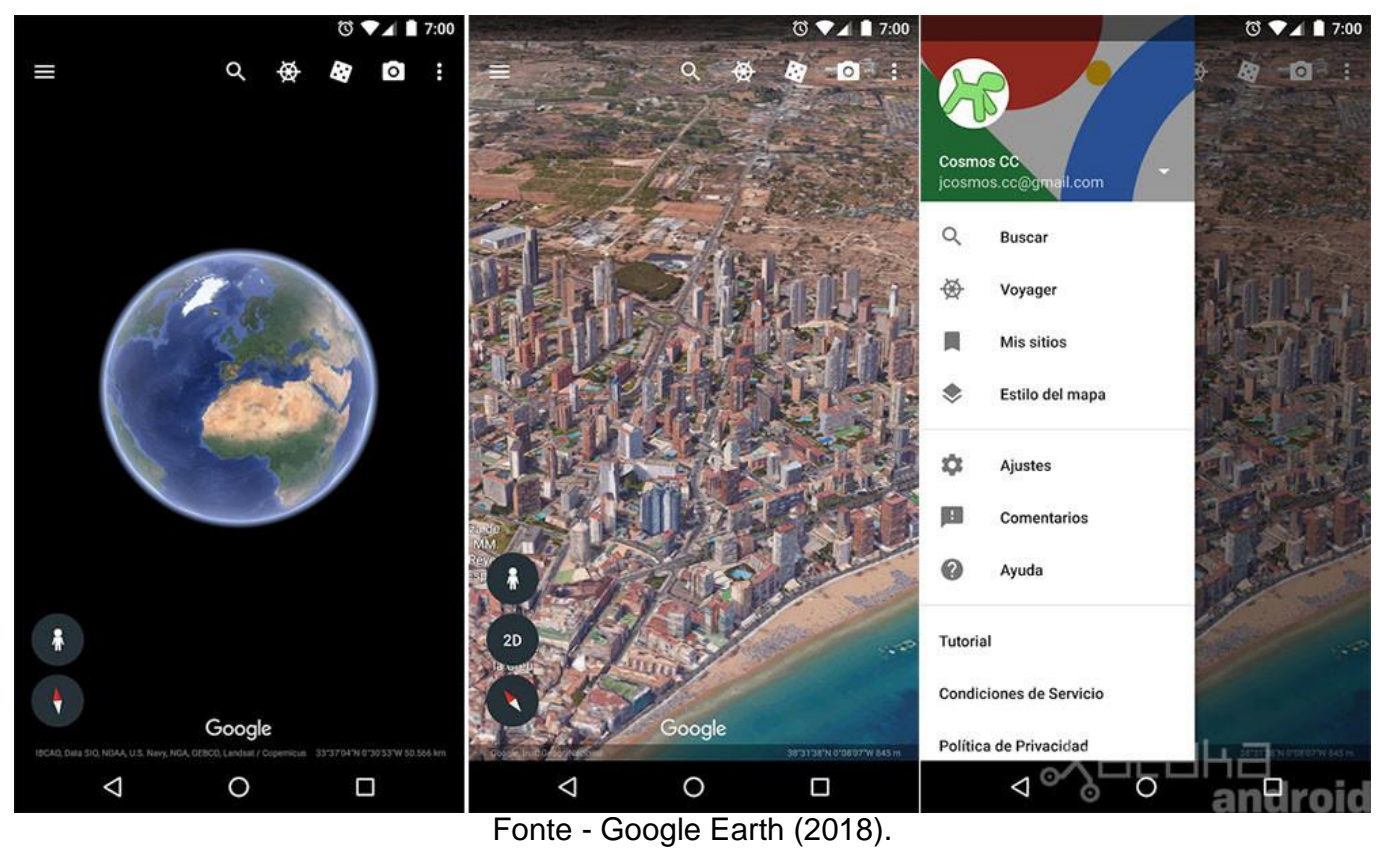

Consequentemente, ainda que seja reconhecida a impossibilidade objetiva de gerar uma representação totalmente fiel da realidade num plano, os mapas continuam a ser produzidos basicamente em duas dimensões, assim como se continua a usar a perspectiva, embora que haja uma incongruência estrutural com as capacidades perceptivas humanas. Esta permanência de formas de representação que contradizem a sua promessa de racionalização objetiva do espaço, explica-se pela fé que perdura na abstração bidimensional do plano, da quadricula, da tela, como condensador confiável da realidade, de redução da complexidade do mundo. Ainda assim, o que temos hoje é inclusive um retorno do valor metafórico do mapa: atualmente é possível afirmar que os mapas não são mais uma representação, mas um ato proposicional (WOOD, 2010), sendo efetivamente comprovado que os mapas não podem representar de forma totalmente fiel a realidade, a qual é inclusive matematicamente muito complexa para sef reduzir a um suporte gráfico. Contudo, esta constatação leva a reafirmar a distinção entre o mundo experimentado e o mundo representado nos mapas. "O globo é medido e registrado, o entorno é experimentado" (INGOLD, 2011, p. 96). Os mapas, por mais exatos e precisos que sejam, não buscam representar o mundo da experiência, mas buscam representar o conhecimento do mundo. Ao reconhecer o mapa como uma representação do conhecimento, deve-se enfocar a dita representação como uma construção apoiada em determinados códigos definidos culturalmente e condicionados por várias tecnologias intelectuais e instrumentais (EDNEY, 1996). O modelo que seguem os mapas é o da imagem que o conhecimento cientifico tem desenvolvido. Uma imagem que, é claro, subordina os princípios abstratos da clareza e da homogeneidade à constatação empírica da infinita complexidade do objeto concreto a representar.

Há, porém, neste desenvolvimento tecnológico um interessante paradoxo. A real novidade dos mapas digitais, não é tanto o 3D, o qual não é mais do que um enfeite arquitetônico que em realidade não elimina o plano da representação, mas é a tentativa por inserir neles novamente a temporalidade, o traço sequencial das vivencias, dos percursos. Atualmente, os mapas digitais trazem, paradoxalmente, a volta de elementos narrativos, não mais por meio de formas icônicas, mas de depoimentos e registros textuais e gráficos que 
estão devolvendo a ideia do percurso, a ideia do mapa como um fato que surge da vivencia em um determinado momento que se prolonga no tempo, e não somente como uma espécie de cristalização atemporal dum dado nível de conhecimento universal do terreno. O maior aporte do digital neste campo não é trazer uma ferramenta mais realista, mas pelo contrário desvendar a falsa imagem da representação plana bidimensional do mundo como confiável e precisa. Já que buscando representar a dimensão que estava faltando, o mapa consegue ser mais fiel a realidade, porque esta não é um plano em três dimensões, mas é curvada, sem uma forma fácil de definir nem, muito menos, de experimentar. A maior riqueza destes novos mapas não é a precisão de satélite nem a sua abrangência potencialmente global, mas o fato de integrar as vivências dos habitantes do território. Neles é possível gerar toda uma série de recursos informativos que são incluídos pelos próprios usuários: é possível associar fotografias particulares a determinados lugares e fornecer informação sobre rotas e percursos; além de ser uma ferramenta em transformação, que integra novas informações e as mudanças que transformam o território. Isto é, torna-se novamente possível integrar o conteúdo da vivencia do sujeito, registrá-lo na ferramenta objetiva que devia representar fielmente o entorno. A vocação extrema de fidelidade trazida pelo digital tem permitido, talvez inesperadamente, à volta da vivencia do sujeito, que a técnica e a ciência tanto tentaram submeter ao longo da história.

Hoje então haveria uma volta do conteúdo metafórico, já que sabemos que o mapa não representa a terra como ela é, mas uma imagem moldada do atual conhecimento, junto com um retorno do elemento narrativo a partir das vivências em tempo real. Ao se juntarem, esses elementos configuram um mapa mais similar àqueles pré-modernos. A sua carga metafórica parece voltar e também a vocação de encenar um microcosmos onde os elementos vitais podem marcar as balizas do território. Todavia, não se trata de um desvio no percurso de desenvolvimento dos mapas, não há uma rachadura do regime representacional por onde penetrou o meshwork para desafiar a ideia de espaço. Pelo contrário, é possível que o próprio projeto de uma representação fiel à realidade do território tenha sido tão bem-sucedida que possa incluir na sua construção os elementos pertencentes ao percurso, à vivencia, ao andarilho; os quais nunca abandonaram o território e continuaram construindo o mundo habitado, ainda que sob o predomínio do mundo do espaço como modelo de representação.

\section{CONSIDERAÇÕES FINAIS}

A partir do contexto histórico na fase de consolidação da Modernidade, os mapas como instrumento (produto cartográfico) e como conceito tiveram uma função central no processo de racionalização do entorno (espaço) físico. Basicamente, buscou-se uma forma de representação do espaço baseada na ideia de se compreender e controlar o território, conseguindo assim, resultados cada vez mais fiéis a uma realidade objetiva em que se procurava um conhecimento eficaz e preciso sobre o mundo, e onde a confiabilidade do mapa estava em sua fidelidade na execução de um modelo impessoal e objetivo do território. Sobre a base de uma lógica abstrata e formal se procurou uma interpretação universal do lugar que ocupamos, deixando de lado a dimensão da experiência, da vivencia que confere sentido à ocupação do espaço, isto é, esquecendo os fluxos, aquilo que percorre o mapa e cria trajetórias que atravessam o plano e a quadricula. Neste empenho de objetividade e precisão dos instrumentos gráficos sobre o mundo, chegamos, porém, no paradoxo atual onde as tecnologias digitais atingem uma fidelidade tão alta que o paradigma do mundo como espaço vê reaparecer ao sujeito andarilho que percorre e ocupa os lugares e deixa suas marcas, suas trilhas, nos instrumentos de leitura e interpretação do território. Nos mapas digitais de hoje à precisão e adaptação eficaz da representação do modelo junta-se a imagem da experiência, do sujeito que concede sentido ao espaço e coloca em discussão sua natureza vácua. $O$ espaço não mais como o vazio entre elementos geográficos que podem se representar e são pontos de referência, mas o espaço como lugar dos percursos, das tangentes que o atravessam, juntando os pontos fixos demarcados nas cartografias.

\section{REFERÊNCIAS}

AKERMAN, J. R. The Structuring of Political Territory in Early Printed Atlases. Imago Mundi, vol. 47, p. 138154, 1995. https://doi.org/10.1080/03085699508592817

ALVARENGA. Luiz Gonzaga de. Geometria e Imagem. 2002. Disponível em: <http://www.scribd.com/doc/11599747/Geometria-Imagem> Acesso em: 10 jul. 2013.

BENJAMIN, W. O Narrador: considerações sobre a obra de Nicolai Leskov. In: Obras escolhidas: magia e técnica. Arte e política. Ensaios sobre literatura e história da cultura. Volume 1. São Paulo: Ed. Brasilense, 1987. p. 197-221. 
CAMPBELL, T. Portolan Charts from the Late Thirteenth Century to 1500, In: HARLEY, J.B.;WOODWARD, D. (Eds) The History of Cartography. Volume 1. University of Chicago Press, 1987. p. 371-463.

COSGROVE, D. Maps, Mapping, Modernity: Art and Cartography in the Twentieth Century. Imago Mundi, vol. 57, No. 1, p. 35-54, 2005. https://doi.org/10.1080/0308569042000289824

DE CERTEAU, M. Relatos de espacio. In: La invención de lo cotidiano I. Artes de hacer. México: Universidad Iberoamericana, 2010. Capítulo IX, p. 127-142.

EDNEY, M. H. Theory and the History of Cartography. Imago Mundi, vol. 48, p. 185-191, 1996. https://doi.org/10.1080/03085699608592841

GOMES, M.; DE BIASI, M. Fontes e técnicas da cartografia medieval portulano, Terra Brasilis (Nova Série) [Online], 4 | 2015.

GOOGLE LLC. Google Earth. Disponível em: https://www.google.com.br/int//pt-BR/earth/. Acesso em: 31 dez.. 2018.

INGOLD, T. Being alive. Essays on movement, knowledge and description. New York: Routledge, 2011. https://doi.org/10.4324/9780203818336

LÉVY, J. De l'espace pour la raison. In: PRADEAU, J. F. (Dir.) Espaces Temps, 62-63. Penser/figurer. L'espace comme langage dans les sciences sociales, p. 19-35, 1996. https://doi.org/10.3406/espat.1996.3985

MATTELART, A. Historia de la sociedad de la información. Barcelona: Paidós, 2002.

PANOFSKY, E. La Perspectiva como forma simbólica. Barcelona: Tusquets, 2003.

QUIÑONES TRIANA, Y. El cine en 3D. Lo hiperreal como una forma de superación del plano bidimensional de representación de la realidad y el ecosistema del nuevo tipo de público: el cíborg virtual. Imagofagia, vol. 8, p. 1-30, 2013.

RAISZ, E. J. Cartografia geral. Rio de Janeiro: Científica, 1969.

TURNBULL, D. Cartography and Science in Early Modern Europe: Mapping the Construction of Knowledge Spaces. Imago Mundi, vol. 48, p. 5-24, 1996. https://doi.org/10.1080/03085699608592830

WIKIMEDIA COMMONS. Low Countries: war of the spanish succession defensive lines. Disponível em: https://commons.wikimedia.org/wiki/File:Low Countries 1700 and entrenched lines.png. Acesso em: 7 nov. 2019.

- Portolan Chart: Old World. Disponível em : https://commons.wikimedia.org/wiki/ File:Portolan Chart (Old World) WDL8954.png. Acesso em: 7 nov. 2019.

WOOD, D. Rethinking the Power of Maps. New York: The Guilford Press. 2010.

Recebido em: 10/04/2019

Aceito para publicação em: 13/11/2019 